\title{
Order-oriented Vocational Education for Migrant Labors during China's Industrial Restructuring
}

\author{
Xiuli Yang \\ College of Economics \\ Henan University of Science and Technology \\ Luoyang, China
}

\begin{abstract}
Migrant labors have become an important source for China's national construction, also a necessary power participating in industrial restructuring which acts as the most urgent issue in China's economical development. In the presence of uncertainty in employment structural readjustment, structural unemployment will definitely be a difficult problem to tackle which raises a higher enquiry for migrant labors' employability. Therefore, vocational education for migrant labors has aroused great attention from all sectors of society. In this article, the author proposed a more targeted education mode for this group of special human resource, namely, order-oriented vocational education aiming to solve practical problems confronting migrant labors.
\end{abstract}

Keywords-order-oriented education; migrant labors; industrial restructuring; employment

\section{INTRODUCTION}

With the stable development in industries, China's economy enjoys a reasonable operation which meets expectations. However, some enterprises suffered difficulties in production or management, which raised an urgent claim for industrial restructuring under the background of tight financial conditions and factor capital increasing. While this may be exciting if this process can be conducted smoothly, it may present some challenges, especially for the migrant labor's employment. This article discusses the ways to tackle the problem of migrant labors' employment during industrial restructuring.

Since the purpose for the study about unemployment is focused on the cause determination, therefore to improve the public policies that affect the unemployed is plausible, including migrant labors who behave fragile in urban labor market, especially during the process of industrial restructuring [1]. China's industrial restructuring contains two parts, one is the industrial structure adjustment, and the other is the industrial structure upgrading [2]. Whatever the connotation for industrial restructuring, the optimization of the labor supply structure must be a key issue arousing

Subject information: The education department of Henan Province social science project: Research on Peasants' participation mechanism and path towards supply of rural public goods under the guidance of supply side reform in Henan Province. Project number: 2017-ZZJH-143.

The Humanities and Social Sciences Association Project of Henan Province The Investigaton and Study on supply situation of Rural Community

Endogenous Public Goods in Henan Province. Project number: SKL-20163259 . enough attention. Accordingly, migrant labors become the most vulnerable people as a result of few practice experience and poor technology who have contributed a lot for China's urbanization in previous years. Such reality puts forward a request for human capital accumulation of migrant labors, and order-oriented vocational education should be a top priority.

It's true that some cities have carried out some vocational education for migrant labors, but such kind of education was received with muted enthusiasm and the results performs as little positive quality feedback information [3][4]. On the contrary, a lot of investigation showed that migrant labors do possess strong education willingness [5][6][7] . The contradiction between migrant labors' strong willingness for vocational education and the low participation percentage of some government hosting education projects indicates that there does exist mismatch and disorder between real demand and potential supply for migrant labors' vocational education. Consequently the doubt is put forward, that is, what kind of vocational education is migrant labors' real demand? What kind of vocational education can raise migrant labors' participation percentage effectively ? This paper is trying to answer the above questions by adoption of order-oriented vocational education.

\section{PURPose AND SignificANCE FOR Migrant LABORS' VOCATIONAL EDUCATION}

To begin with this paper will provide a brief background on the issue about migrant labors' vocational education. During the period of China's 13th Five-Year, the total employment contradiction and structure contradiction interweave together while structural problems become the major obstacle concerning employment. Comparatively speaking, the problem about migrant labors' employment seems prominent which requires sufficient attention.

Recently some agricultural surplus labors still stay in cities despite some has chosen to return rural areas due to China's industrial restructuring. However, labor barren still lingers cities which demonstrates a different denotation, namely qualified labors are in short supply. Accompany with the rapid development of social economy and the higher demand for employment, the contradiction appears striking between labor knowledge reserve and industrial structures which results in the inevitable paradox, that is, ordinary 
surplus labors are unable to take positions confined to highly talented professionals. Therefore, it's of great importance to train migrant labors in the hope of enhancing their technological level which is necessary to accelerate social economy development.

Reform and development are at a critical period which puts forward higher demand for the quality of human resource. If a country develops its economy not by hiring more labors but by adopting new technology and equipment and improving labors cultural and technical proficiency, then the ability of its material production sector to absorb the workforce will be limited [8]. According to relative investigation, the role of material and human capital is significant, while labor power and technological level is weak in economic growth in the whole nation. Meanwhile, current capability for migrant labor can't meet the needs of the social and economic development and industrial restructuring, which strongly calls for vocational education aiming at this group of surplus labors. Vocational education can contribute to migrant labors' successful realization of urbanization, professional quality accumulation and enhancement of living quality. Thus, vocational education plays an inevitable role in the social and economic development as well as in the nurturing of high technology talents.

\section{PROBLEMS IN VOCATIONAL EDUCATION FOR MIGRANT LABORS}

Vocational education for migrant labors has aroused great attention and concern both from the society and the government; it still lingers at a unsatisfactory situation due to its incomplete popularity which inevitably runs into difficulties to a certain extent, which performs as follows.

Firstly, lack of motivation among migrant labors. Rural areas stay more inaccessible geographically which confines migrant labors' keen sense to get in touch with the new. On one hand, their simple thinking mode and unfavorable living condition lead to their lack of intellectual curiosity, firm faith and long-range ideal [9]; On the other hand, China's urban-rural dual system prevents migrant labors from enjoying reasonable well-being which can manifest impartiality and objectivity simultaneously. Even if there is no inferiority complex lingering migrant labors, most of them would consider the value embodied in vocational education and its opportunity cost, furthermore become unwilling to overcome self-abased mentality and comprehensively improve their adaptability through vocational education.

Secondly, the system of vocational education performs unsound. At present, most of the education institutions intend to seize the opportunity to make profits although hit the slogan about vocational education for migrant labors. It's these informal institutions that make migrant labors' vocational education a chaos instead of a preferable channel for skill accumulation. Apart from the above confusion involved in migrant labors' vocational education, the lack of corresponding supervision organization also exists as a major cause for the gloomy situation facing migrant labors.
Thirdly, poor education quality prevents migrant labors from achieving ideal results. Most of the education institutions are not specialist in professional education while focus on the issues as the following, such as how to find a job, how to be adapted to urban circumstances, and so on. Apparently the education contents are relative to migrant labors future in cities, however, it seems too macroscopic while possesses little appropriate skills. Therefore, the result for education adopted by relative institutions cannot provide well-directed drilling that can guarantee favoring conversion to actual work, which is a significant prerequisite for migrant labors to equip themselves with bargaining power. Besides, the shortage of qualified trainers exists as another serious problem. The role for vocational education performs as teaching migrant labors vocational skills which call for qualified staff to engage in. whereas, the teaching staff seems intermingles between good and bad nowadays working in migrant labors vocational education and the education effect can't be evaluated scientifically.

Fourthly, the phenomenon of concurrent occupation among migrant labors seems common which leads to nonspecialized consequences to a certain degree. The vocational education aiming at migrant labors puts forward the claim for the trainees to conduct continuous learning, while migrant labors have to take part-time migration as well as part-time vocational education which will definitely affect education effect. How to deal with time allocation and income structure lingers as a major problem under the guidance of low per capita income. it's the fact that the rural migrant labors into the city part of the restrictive policies of the industry gradually relaxed, free movement of labor between urban and rural areas become possible, but it really results in negative effect on the vocational education due to the reality that migrant labors can't concentrate all their attention on learning and skills accumulation.

Finally, it's lack of legal protection for migrant labors vocational education. There do exist a certain number of vocational education with migrant labors as targeting audience executed by some education institutions, however, hardly no relative vocational qualification certificate is available implemented by relative authorities which can provide evidence for migrant labors' expense on time and money as well. What's worse, some employers don't accept the verification migrant labors get from education institutions. Obviously the mechanism is not accessible between education institutions and employers for migrant labors that definitely lead to the mismatch in the labor market and aggravation of unemployment. Furthermore, some education institutions take some dangerous education forms which is inclined to cause accidents, thus migrant labors choose to neglect due to its shortage in guarantee about the safety of life and property.

\section{CORRESPONDING COUNTERMEASURES TOWARDS Migrant LABORS' VOCATIONAL EDUCATION}

First of all, promote the advantages vocational education takes. According to prospect theory raised by Kahneman, D. and Tversky, A.(1979), people's decision making is inclined to deviate from rational expectation under uncertainty. The 
accumulation of skills must follow the principle of gradual improvement, therefore, migrant labors in different career stages possess various work efficiency, which is showed in "Fig. 1" that performs like a "smiling curve". According to the following curve, the optional learning style appropriate for migrant labors who are seeking jobs in labor market should be order-oriented education; while for migrant labors who have engaged in a job the suitable manner for them ought to be learning by doing which is considered to contribute a lot for their professional development and selfgrowth; the way of self-education must be plausible for migrant labors who have accumulated some experience in real job.

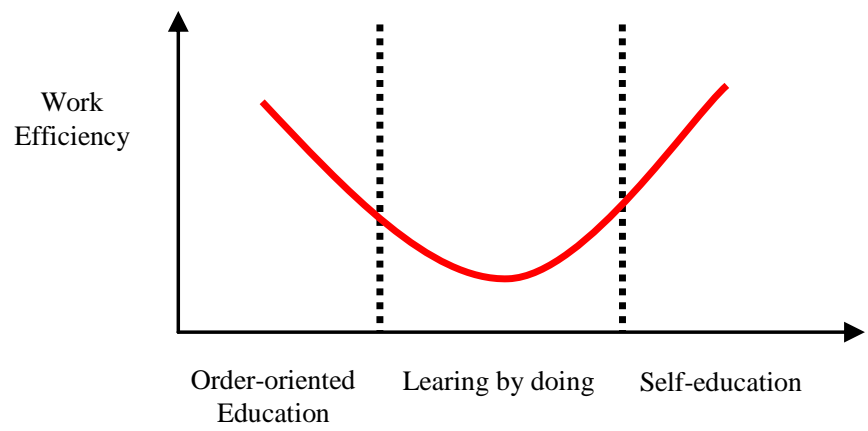

Fig. 1. Reemployment smile curve.

Second, strengthening support from the government. Migrant labors vocational education undertakings need financial support in every aspect, therefore, it is necessary for the government to invest plenty of money to form a stable education system. In major exporters of migrant labors, the government is obligated to encourage vocational education in the premise of human resources' comprehension about the relationship between education practice and their bargaining power in future labor market. In recipient regions of rural labors, the government should be liable for popular propaganda about necessity for migrant labors' vocational education in the aspect of improving actual operation efficiency considerably, and it's also plausible for the prevailing of migrant worker-friendly policy and some relative well-being. Besides, it's not only the government's responsibility for migrant labors' vocational education operation, but also the integration of all kinds of social resources, such as enterprises resources and educational resources. Only through specialized and systematical vocational education can migrant labors receive useful contents which can be applicable for future job.

Lastly, improvement of relevant legal system should be feasible. In view of the reality that some lawbreakers intend to seek benefits for themselves through migrant labors vocational education, the government and relevant departments are proposed to make relevant policies, perfect the laws and regulations, and create a unified and standard labor market environment and order that facilitate fair competition. Migrant labors are vulnerable groups who are also necessary labor resource for industrial restructuring; the government should take consideration about their rights and interests protection during the process of vocational education. Standardizing education institutions, creating a reasonable and safe education environment, improving migrant labors' well-being and living standard, and then encourage migrant labors to play their important role in industrial restructuring and participate in the urbanization process confidently.

\section{REFERENCES}

[1] N. Gregory Mankiw. Macroceonomics, (6 ${ }^{\text {th }}$ edition), People's University Publication House, 2009, p150-159.

[2] Su Dongshui, Industry Economics, edition 3, Higher Education Press Beijing, 2010, 205-206

[3] Wang Haigang, Huang Shaoan, Li Qin, Luo Fengjin. The Effect of Vocational Education on Non-farming Incomes [J].Economic Research Journal, 2009(9):128-151

[4] Huang Zuhui, Yu Ning. Determinants in Landless Farmers' Willingness to Accept Education and Its Solutions [J]. Journal of Zhejiang University (Humanities and Social Sciences), 2007(3): 135142

[5] Xie Yong, Huang Chenggui. Analysis of Migrant Labors' Willingness to Participating in Vocational Education of Different Generations [J]. The World of Survey and Research. 2011(1): 30-33

[6] Yang Xiaojun, Chen Hao. Analysis of Influential Factors for Migrant Labors' Skill Education Willingness in Urban Areas [J]. Chinese Rural Economy. 2008(11):46-53

[7] He Zhen, Li Chen. Solving the Dilemma of the New Generation Migrant Labors' Education with High Willingness and Low Participation Rate---From the Aspect of Human Capital Characteristics and Enterprise Education [J]. Educational Research, 2013(2):105-110

[8] Kahneman, D.,\&Tversky, A. (1979). Prospect theory: An analysis of decision under risk. Econometrica, 47, 263-291

[9] Su Lifeng, Chen Jianwei. A Study on Higher Education Graduates Supply and Allocation under the Background of Industrial Structure Adjustment. Chinese Journal of Population Science, 2016, (4):2-15 